\title{
Investigation of laser heat treated Monel 400
}

\author{
Mateusz Kukliński ${ }^{1,}$, Aneta Bartkowska $^{1}$, and Damian Przestacki ${ }^{1}$ \\ ${ }^{1}$ Poznań University of Technology, Faculty of Mechanical Engineering and Management, Pl. Marii \\ Skłodowskiej-Curie 5, 60-965 Poznań, Poland
}

\begin{abstract}
In this research, Monel metal was laser heat-treated for microstructural, microhardness and roughness investigation. The treatment is an initial stage for welding Monel without additional material for structural elements. The treatment was carried out with diode laser TruDiode 3006 which allows to reach a power of $3 \mathrm{~kW}$. The material was treated with a constant laser beam power, equal to $1400 \mathrm{~W}$, and four different laser beam velocities: $5,25,50$ and $75 \mathrm{~m} / \mathrm{min}$. The distance between single laser tracks was $0,5 \mathrm{~mm}$ in every experimental series. It was found that laser heat treatment of Monel does not influence its hardness. The depth of melted areas is decreasing with an increasing laser beam velocity. The melted area manufactured with laser beam velocity equal to $5 \mathrm{~m} / \mathrm{min}$ is about $350 \mu \mathrm{m}$. Increasing the laser beam velocity to 75 $\mathrm{m} / \mathrm{min}$ causes depth reduction to about $100 \mu \mathrm{m}$. The melted areas are built with column crystals oriented in the direction of heat dissipation perpendicular to the heating direction.
\end{abstract}

\section{Introduction}

Monel 400 alloy, due to its high corrosion resistance, is mainly applied for constructions and functional parts where aggressive environment occur. These could be acid, alkali and salt but also seawater and polluted urban air. Monel 400 shows excellent resistance among others against sulfuric, hydrofluoric, phosphoric and organic acids. Moreover, this material is easy to shape by forming and machining processes, contrary to other nickel superalloys [1,2-4].

It was air contamination that forced architects and engineers to use corrosion-resistant material for buildings covering. Monel 400 was a perfect solution for this requirement. The first major roofing installation made of Monel was Pennsylvania Railroad Station in New York City in 1909. The potential life of this roof was estimated as 300 years and lasted the life of the building. Some other buildings with Monel covering are Museum of Art in Philadelphia, PA, Pentagon Building, National Cathedral and National Art Gallery - all three of these are placed in Washington, D.C. $[5,6]$.

Laser technologies which are applied within a broad spectrum of applications, are also used for processing construction elements. The ability to propagate in a straight line and the possibility to easy adjust beam's power make laser the most precise heat source. Moreover, due to its concentration in small area, laser provides only minor changes in material

\footnotetext{
*Corresponding author: mateusz.kuklinski@doctorate.put.poznan.pl
} 
microstructure. Four major categories of laser material processing are forming, joining, machining and surface engineering. In manufacturing building roofs and facades laser is mainly used for welding, cutting and surface finishing [7-9,10].

This research focuses on analyzing the influence of laser beam scanning velocity on Monel 400 properties after laser heat treatment. The survey is aimed at prospective welding construction elements made of Monel without additional material.

\section{Research methodology}

\subsection{Material}

The material investigated in this experiment was Monel 400. Its chemical composition is given in Table 1. Microstructure of this alloy is built of nickel-copper solid solution. Because of great solubility of nickel and copper in all proportions, it is a single-phase alloy. Before the laser heat treatment, material was cut to obtain specimens of dimensions $30 \mathrm{~mm} \times 20 \mathrm{~mm} \times 12 \mathrm{~mm}$.

Table 1. Chemical composition of Monel 400 alloy.

\begin{tabular}{|c|c|c|c|c|c|c|}
\hline Si [\%] & Cu [\%] & Fe [\%] & Mn [\%] & C [\%] & S [\%] & Ni [\%] \\
\hline $\max 0.5$ & $28-34$ & $\max 2.5$ & $\max 2.0$ & $\max 0.3$ & $\max 0.024$ & bal. \\
\hline
\end{tabular}

\subsection{Laser heat treatment}

Laser heat treatment was carried out with a diode laser TRUMPF TruDiode 3006. This laser is based on single diode modules which allow to reach power of $3 \mathrm{~kW}$. To manipulate the location of laser beam, it was integrated with KUKA KR16-2 robot. During laser track manufacturing, laser beam was started above and turned off behind the specimen area to make sure that laser beam scanning velocity is equal on an entire laser track. The scheme of described system is presented in Figure 1.
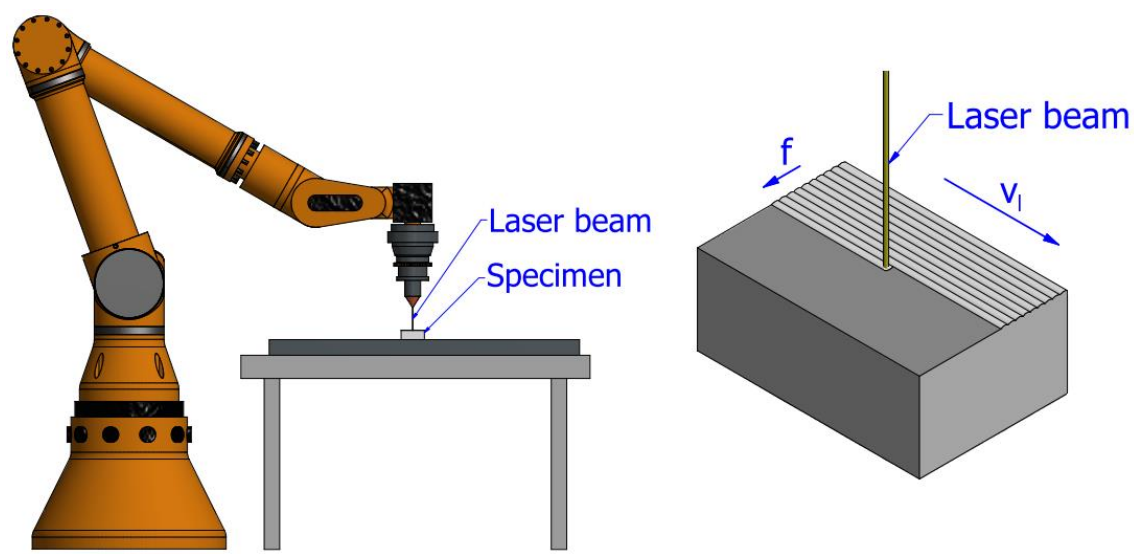

Fig. 1. Scheme of Monel 400 laser heat treatment process.

Each sample was laser heat treated on side of dimensions $30 \mathrm{~mm}$ x $20 \mathrm{~mm}$. Constant parameters were laser beam power $P=1400 \mathrm{~W}$, laser beam diameter $d_{l}=1 \mathrm{~mm}$ and distance between laser tracks $f=0.5 \mathrm{~mm}$. The samples were treated with different laser 
beam scanning velocity $v_{l}$ ranged from $5 \mathrm{~m} / \mathrm{min}$ to $75 \mathrm{~m} / \mathrm{min}$. A detailed summary of laser heat treatment parameters is given in Table 2.

Table 2. Laser heat treatment parameters.

\begin{tabular}{|c|c|c|c|c|}
\hline $\begin{array}{c}P \\
{[\mathbf{W}]}\end{array}$ & $\begin{array}{c}q \\
{\left[\mathrm{~kW} / \mathrm{cm}^{2}\right]}\end{array}$ & $\begin{array}{c}v_{l} \\
{[\mathrm{~m} / \mathrm{min}]}\end{array}$ & $\begin{array}{c}d_{l} \\
{[\mathrm{~mm}]}\end{array}$ & $\begin{array}{c}f \\
{[\mathbf{m m}]}\end{array}$ \\
\hline \multirow{4}{*}{1400} & \multirow{4}{*}{178.3} & 5 & \multirow{4}{*}{1} & \multirow{4}{*}{0.5} \\
\hline & & 25 & & \\
\hline & & 50 & & \\
\hline & & 75 & & \\
\hline
\end{tabular}

\subsection{Samples preparation}

In order to obtain metallographic microsections for microstructural investigation, samples were cut across laser tracks and cutting surfaces were grinded with abrasive papers of grit ranged from 120 to 2000 . Then, specimens were polished for 20 minutes and etched with Marble's reagent.

\subsection{Visual investigation}

First step of visual investigation was observation of laser treated surface. For this purpose stereomicroscope Stereo Discovery V.20 was used. Pictures for microstructural investigation were taken using light microscope Opta-Tech of series LAB40. Besides from analysis of microstructure, the obtained pictures were used for measuring dimensions of laser tracks and microhardness imprints. These measurements were carried out using Axio Vision software.

\subsection{Microhardness and roughness testing}

Indentations for microhardness measurement were fabricated with Zwick 3212B tester with load $F=0.9807 \mathrm{~N}$. Roughness of laser tracks was measured using profilographometer Hommel Tester H500.

\section{Results and discussion}

\subsection{Laser heat treated surface investigation}

The first stage of investigation specimens after laser heat treatment was taking pictures of processed surface. The chosen images are shown in Figures 2a-d. Based on these images, it was initially concluded that increasing laser beam scanning velocity from $5 \mathrm{~m} / \mathrm{min}$ to $25 \mathrm{~m} / \mathrm{min}$ results in decreasing the width of laser tracks. However, further decreasing the size of laser tracks was not found with enhancing laser beam scanning velocity to $50 \mathrm{~m} / \mathrm{min}$ and $75 \mathrm{~m} / \mathrm{min}$. Furthermore, laser tracks shown in Figure 2a seem to overlap each other, unlike the others.

Besides from laser tracks size, it can be also seen that surface treated with $v_{l}=5 \mathrm{~m} / \mathrm{min}$ is probably more rough than these shown in Figures b, $c$ and d. Therefore, surface quality was separately investigated, the results are described in paragraph 3.2. 


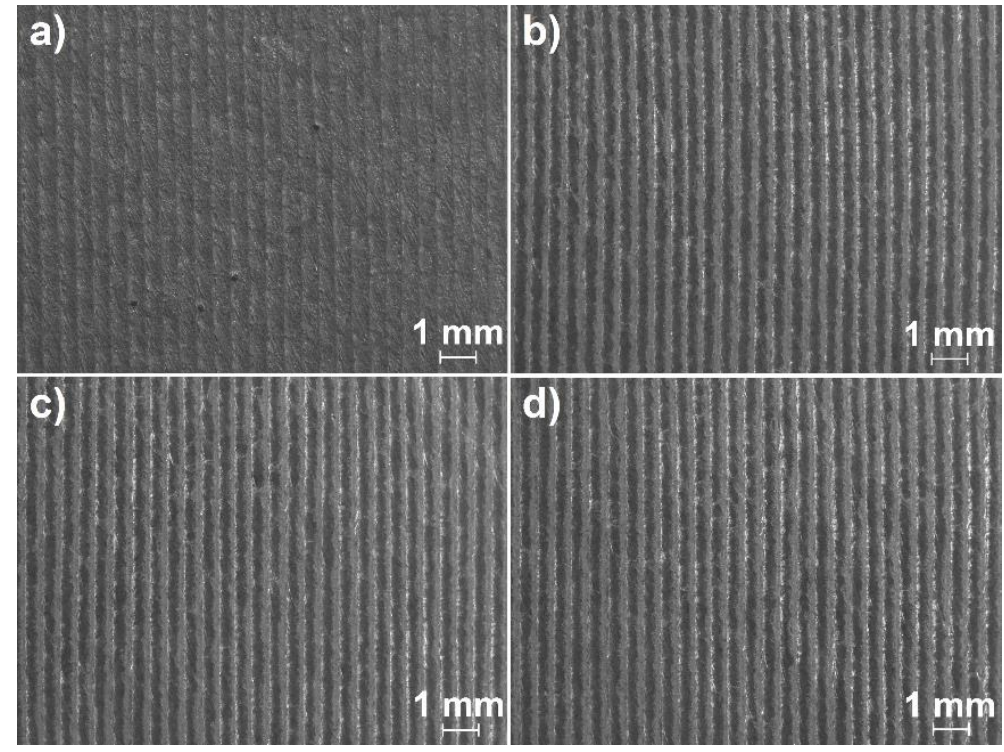

Fig. 2. Surface of Monel 400 alloy after laser heat treatment with laser beam scanning velocity: a) $5 \mathrm{~m} / \mathrm{min}$, b) $25 \mathrm{~m} / \mathrm{min}$, c) $50 \mathrm{~m} / \mathrm{min}$, d) $75 \mathrm{~m} / \mathrm{min}$.

\subsection{Roughness testing}

Roughness was measured to determine Monels' surface quality after laser heat treatment. The obtained results in the form of roughness parameters $S_{a}$ and $S_{z}$ are shown in Figure 3 with their graphical representation for easier comparison. $S_{a}$ parameter is an average roughness deviation and $S_{z}$ is a ten-point surface irregularities height. Additionally, exemplary 3-dimensional profile of surface processed with scanning laser beam velocity $v_{l}=25 \mathrm{~m} / \mathrm{min}$ is shown in Figure 4.

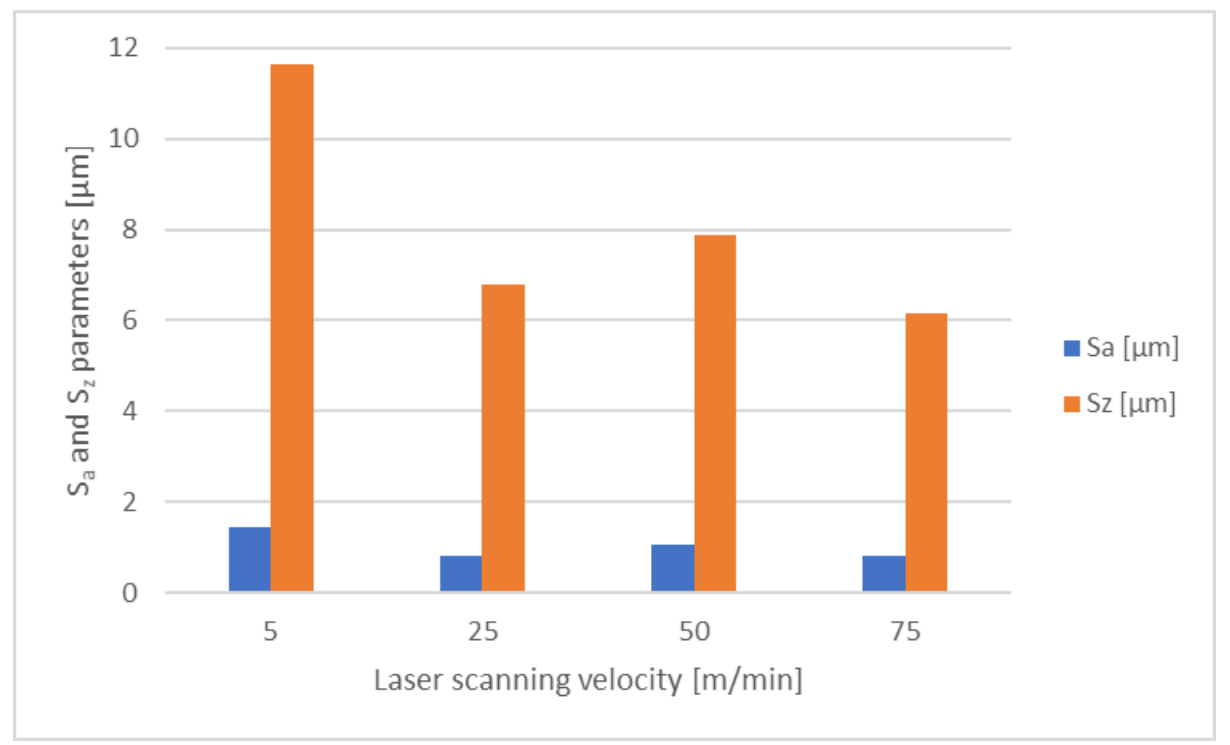

Fig. 3. The influence of laser beam scanning velocity of roughness paramteres $S_{a}$ and $S_{z}$. 
Considering the obtained values of roughness parameters it is clear that, as aforementioned, surface is more smooth on surfaces treated with higher scanning laser beam velocities. However, it seems that increasing laser beam scanning velocity from $25 \mathrm{~m} / \mathrm{min}$ to $75 \mathrm{~m} / \mathrm{min}$ does not still lower the roughness significantly. Average roughness parameter $S_{a}$ of surfaces produced with scanning speed greater than or equal to $25 \mathrm{~m} / \mathrm{min}$ is about $36 \%$ lower than for $5 \mathrm{~m} / \mathrm{min}$. Average $S_{z}$ parameter of these is approximately $40 \%$ lower than $S_{z}$ of surface produced with the lowest laser beam scanning velocity.

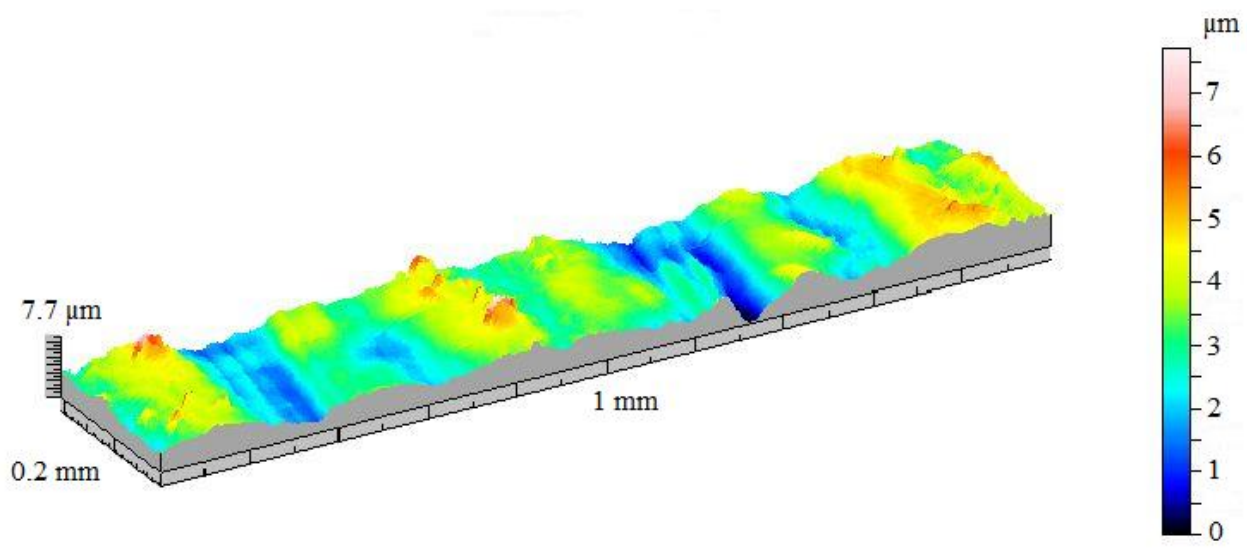

Fig. 4. 3-dimensional roughness profile of surface processed with laser beam scanning velocity $\mathrm{v}_{1}=25 \mathrm{~m} / \mathrm{min}$.

\subsection{Microstructure investigation}

Cross-section microstructure of laser heat treated surfaces are shown in Figure 5. They are sorted in ascending laser beam scanning speed order. Figure 6 presents more detailed views of laser tracks produced with scanning velocities equal to $5 \mathrm{~m} / \mathrm{min}$ and $75 \mathrm{~m} / \mathrm{min}$. The areas shown in Figure 6 are marked with white rectangles in Figure 5.

It can be clearly seen in Figure 5 that increasing laser beam scanning velocity results in decreasing the depth of laser tracks. Their depths were measured and obtained results and average values are given in Table 4. It is worth noting that laser track depth lower approximately $74 \%$ with enhancing laser beam scanning velocity from $5 \mathrm{~m} / \mathrm{min}$ but remain almost constant with increasing the scanning speed up to $75 \mathrm{~m} / \mathrm{min}$.

Table 3. Laser tracks' depths for different laser beam scanning velocities.

\begin{tabular}{|c|c|c|c|c|c|c|}
\hline \multirow{2}{*}{$\begin{array}{c}\boldsymbol{v}_{\boldsymbol{l}} \\
{[\mathbf{m} / \mathbf{m i n}]}\end{array}$} & \multicolumn{5}{|c|}{ Number of measurement, results $[\boldsymbol{\mu \mathrm { m } ]}$} & \multirow{2}{*}{$\begin{array}{c}\text { Average } \\
{[\boldsymbol{\mu m}]}\end{array}$} \\
\cline { 2 - 6 } & $\mathbf{1}$ & $\mathbf{2}$ & $\mathbf{3}$ & $\mathbf{4}$ & $\mathbf{5}$ & \\
\hline $\mathbf{5}$ & 355 & 366 & 366 & 363 & 360 & $\mathbf{3 6 2}$ \\
\hline $\mathbf{2 5}$ & 93 & 94 & 90 & 99 & 94 & $\mathbf{9 4}$ \\
\hline $\mathbf{5 0}$ & 93 & 96 & 90 & 94 & 92 & $\mathbf{9 3}$ \\
\hline $\mathbf{7 5}$ & 92 & 94 & 94 & 35 & 93 & $\mathbf{9 4}$ \\
\hline
\end{tabular}




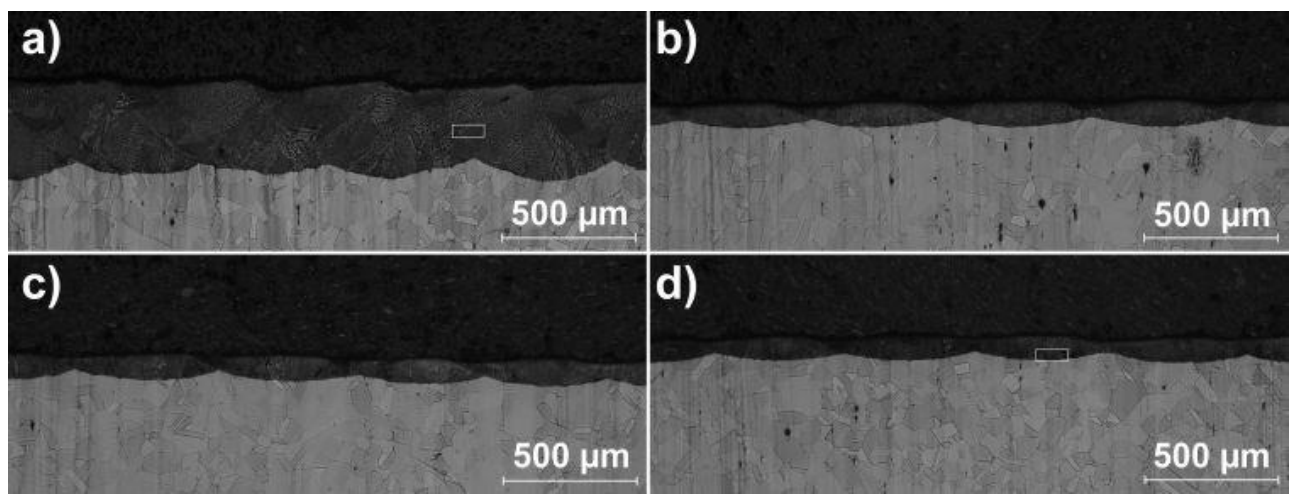

Fig. 5. Microstructures of multiple laser tracks manufactured with: a) $\left.\mathrm{vl}_{1}=5 \mathrm{~m} / \mathrm{min}, \mathrm{b}\right) \mathrm{vl}_{\mathrm{l}}=25 \mathrm{~m} / \mathrm{min}$, c) $\left.\mathrm{v}_{1}=50 \mathrm{~m} / \mathrm{min}, \mathrm{d}\right) \mathrm{v}_{\mathrm{l}}=75 \mathrm{~m} / \mathrm{min}$.

As observed in Figure 6, the morphology of laser tracks includes column crystals of different lengths. These crystals are mostly oriented in the direction of heat dissipation. Column crystals in Figure 6a are larger than these in Figure 6b. Heat dissipation is directed mainly to the surface but also to the boundary between laser track and substrate.

It was found that all laser tracks are free of cracks and voids. This provides evidence that if the welding process is carried out with parameters used in this research, there are no critical stresses in material during quick solidification. For the sake of confirmation that after laser heat treatment properties of Monel 400 remain constant microhardness measurement was carried out, its results are described in paragraph 3.4.

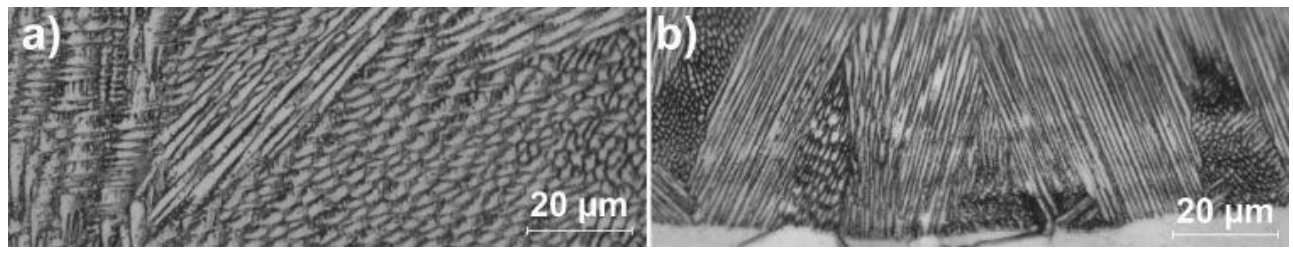

Fig. 6. Microstructures of laser tracks manufactured with: a) $\mathrm{v}_{\mathrm{l}}=5 \mathrm{~m} / \mathrm{min}$, b) $\mathrm{v}_{\mathrm{l}}=75 \mathrm{~m} / \mathrm{min}$.

\subsection{Microhardness measurement}

Results of microhardness testing carried out on cross-sections of Monel 400 after laser heat treatment are shown in Table 4. Every specimen shows three indentations fabricated in laser track area and three in the substrate. In Figure 7 a dark-field picture of specimen treated with $v_{l}=50 \mathrm{~m} / \mathrm{min}$ is shown for comparison of microhardness indentation sizes in laser-heated area and the substrate.

Average microhardness of laser tracks is $165.3 \mathrm{HV} 0.1$ and of substrate - 163.2 HV0.1. Average microhardness of laser tracks was calculated on the basis of values given in Table 4. An insignificant difference between these two values leads to conclusion that laser heat treatment of Monel 400 does not affect its microhardness. However, microhardness of laser tracks produced with $v_{l}=5 \mathrm{~m} / \mathrm{min}$ is slightly lower than the others and it was interpreted as a result of larger column crystals occurring. 
Table 4. Average values of microhardness measurement on specimens laser heat treated with different laser beam scanning velocity.

\begin{tabular}{|c|c|c|}
\hline $\begin{array}{c}\boldsymbol{v}_{\boldsymbol{l}} \\
{[\mathbf{m} / \mathbf{m i n}]}\end{array}$ & $\begin{array}{c}\text { Average laser } \\
\text { track's HV0.1 }\end{array}$ & $\begin{array}{c}\text { Average } \\
\text { substrate's } \\
\text { HV0.1 }\end{array}$ \\
\hline 5 & 159.5 & \multirow{2}{*}{} \\
\cline { 1 - 2 } & \multirow{2}{*}{163.2} \\
\hline 50 & 168.9 & \\
\hline 75 & 162.8 & \\
\hline
\end{tabular}

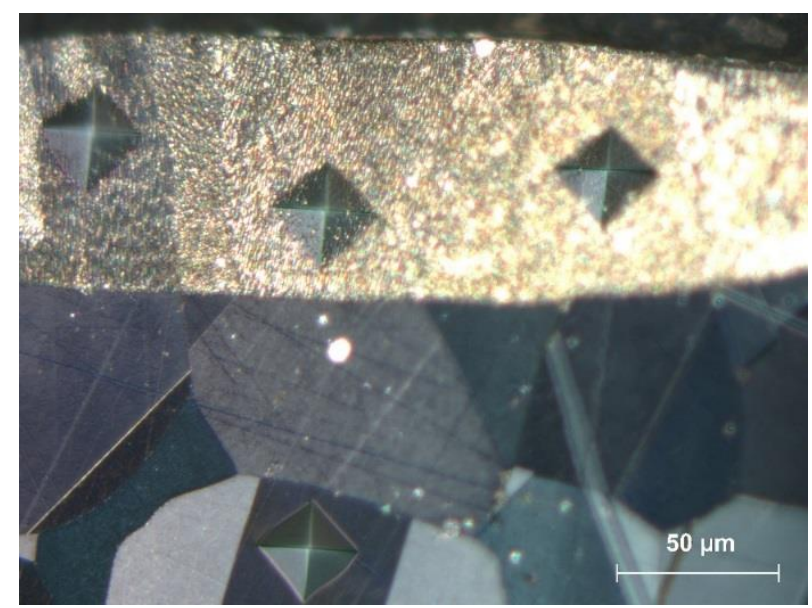

Fig. 7. Microhardness indentations fabricated in laser track area and the substrate of specimen processed with $v_{l}=50 \mathrm{~m} / \mathrm{min}$.

\section{Conclusions}

The paper presents an investigation of influence of laser heat treatment carried out with different laser beam scanning velocities on Monel 400 alloy. The research results led to the following conclusions:

1. Increasing the laser beam scanning velocity from $5 \mathrm{~m} / \mathrm{min}$ to $25 \mathrm{~m} / \mathrm{min}$ causes the laser track dimensions reduction by approximately $74 \%$ but further enhancing of the scanning speed does not affect the depth of heated zone.

2. Laser heat treated surfaces are more smooth if laser beam scanning velocity equal to $25 \mathrm{~m} / \mathrm{min}$ is applied for the process. However, increasing laser beam scanning velocity to $50 \mathrm{~m} / \mathrm{min}$ and $75 \mathrm{~m} / \mathrm{min}$ have no influence on the roughness.

3. Laser tracks manufactured in this research are free of cracks. It proves that there are no critical stresses in material during quick solidification if the process is carried out with aforementioned parameters.

4. Microhardness of laser heat treated Monel 400 does not change as a result of material remelting. It is crucial for producing weldments whose mechanical properties are identical to base metal parameters. 


\section{References}

1. http://www.specialmetals.com/assets/smc/documents/alloys/monel/monel-alloy400.pdf: Monel alloy 400, Publication Number SMC-053, Special Metals Corporation (2005)

2. K.D. Ramkumar, N. Arivazhagan, S. Narayanan, D. Mishra, Hot Corrosion Behavior of Monel 400 and AISI 304 Dissimilar Weldments Exposed in the Molten Salt Environment Containing $\mathrm{Na}_{2} \mathrm{SO}_{4}+60 \% \mathrm{~V}_{2} \mathrm{O}_{5}$ at $600^{\circ} \mathrm{C}$, Materials Research 17(5), 1274-1284 (2014)

3. J.H. Rosenfeld, N.J. Gernert, Life Test Results for Water Heat Pipes Operating at $200^{\circ} \mathrm{C}$ to $300^{\circ} \mathrm{C}$, AIP Conf Proc 969, 123-130 (2008)

4. D.B. Sarraf, W.G. Anderson, Heat pipes for high temperaturę thermal management, Proceedings of the ASME InterPack Conference 1, 707-714 (2007)

5. L.E. Shoemaker, G.D. Smith, A century of Monel metal: 1906-2006, JOM-J Min Met Mat S 58(9), 22-26 (2006)

6. http://www.upenn.edu/pennpress/gallery/prr/prrpix.html: The Pennsylvania Railroad, Volume 1: Building an Empire, 1846-1917, Albert J. Churella (2012)

7. B. Adak, P. Nash, D. Chen, A. Swinglo, Microstructural characterization of laser cladding of Cu-30Ni, J Mater Sci 40, 2015-2054 (2005)

8. A. Bartkowska, M. Kukliński, P. Kieruj, The influence of laser heat treatment on the geometric structure of the surface and condition on the surface layer and selected properties of Waspaloy, MATEC Web Conf 121, 03006 (2017)

9. D.B. Sarraf, W.G. Anderson, Heat pipes for high temperaturę thermal management. Proceedings of the ASME InterPack Conference 1, 707-714 (2007)

10. D. Przestacki, A. Bartkowska, M. Kukliński, Influence of laser heat treatment on microstructure and properties of surface layer of Waspaloy aimed for laser assisted machining. Int J Adv Manuf Tech 93(9-12), 3111-3123 (2017) 